\title{
ECOLOGICAL SECURITY PATTERN FOR THE LANDSCAPE OF MESOSCALE AND MICROSCALE LAND: A CASE STUDY OF THE HARBIN CITY CENTER
}

\author{
Zhang YUANJINGa, b, Yu BINYANG ${ }^{c}$, Muhammad Aqeel ASHRAF ${ }^{\mathrm{d}, \mathrm{e}}$ \\ ${ }^{a}$ School of Resources and Environment, Northeast Agricultural University, Harbin 150030, China \\ ${ }^{b}$ Heilongjiang Urban Planning Surveying Design and Research Institute, Harbin 150040, China \\ 'Ministry of Housing and Urban-Rural Development of the People's Republic of China, Beijing 100835, China \\ ${ }^{d}$ Department of Geology, Faculty of Science, University of Malaya 50603 Kuala Lumpur, Malaysia \\ ${ }^{e}$ Faculty of Science \& Natural Resources, Universiti Malaysia Sabah 88400 Kota Kinabalu Sabah Malaysia
}

Submitted 01 Dec 2014; accepted 30 Mar 2015

\begin{abstract}
The city center planning based on the ecological security pattern of the landscape plays an important role in protecting the healthy operation of the urban ecological environment. This paper takes the city of Harbin of Heilongjiang Province as the target of research, the data during 2011 and 2012 relating to the overall urban planning of Harbin as the data source, and the extraction of the study domain based on the principle of landscape ecology as the ecological source. Also, we take the cumulative cost distance model to create the ecological corridor and the ecological nodes, build the spatial pattern of the city center based on the ecological security pattern of the landscape, and develop the strategy to protect the ecological security pattern of the city center landscape. This study has a pivotal reference value for guiding the city's overall planning and protecting the ecological environment of the region.
\end{abstract}

Keywords: city center, ecological security pattern of the landscape, the cumulative cost distance model, city planning.

\section{Introduction}

Historically, a city is the largest creation of human society that also has one of the most negative effects upon the evolution of human society, as due to a great deal of destruction of the natural ecological environment, it is unable to recover. Urban construction is facing many eco-environmental issues. Recently, a large number of experts and scholars are calling for urban redevelopment on the basis of urban ecology (Yang 2010). Consequently, in view of the pattern for the ecological security of landscape and in the framework of the construction of the land layout in the city center, it is urgent to develop a rational urban master plan. Due to the city center land layout planning supported by the experience of urban planners, the stacking layers, and the limited public participation in the past (Qin et al. 2010), the scientific nature and the rationality of land layout has been questioned. Affected by the uncertainties in urban social and economic development, it is hard to predict the urban development situation in the next 15 to 20 years. But the ecological land as a maintenance of urban ecological security in urban development can be achieved in rigid conditions, and is necessary for the sustainable development of the city.

Ecological security pattern refers to the landscape spatial pattern of the potential ecological system. There are some potentialities in developing the landscape spatial pattern of ecological system. It is composed of some key parts of the landscape and their location and space, and is significant for the maintenance or control of a certain ecological process in the area (Rong et al. 2011; Ma et al. 2004; Li et al. 2004; Yang 2014; Yang et al. 2011; Yu et al. 2009; Hu et al. 2011). The planning of the urban ecological security pattern should break through the disciplinary boundaries of urban planning to look for theoretical support from ecology, especially from landscape ecology (Ren X., Ren S. 2009). Zulkifly pointed out in the report "The overall planning of Macau: Ideas and inspiration" that ecological security is one of the core contents of public security as well as one of the contents of structural control of the technological change of the overall urban

Corresponding author: Muhammad Aqeel Ashraf

E-mail: aqeelashraf@um.edu.my 
planning in the future (Zulkifly et al. 2014a,b). The change from the planning of scale expansion to that of boundary under the environment and resource restrictions constitutes one of the "four changes" of the new round of the overall urban planning of Shanghai. At present, the existing research on the ecological security pattern mostly focuses on large scale areas. However, the contradictions between the natural ecosystem and the construction of the city center of a small and medium scale stand out. In terms of the philosophy of the living environment, the ecological environment of a small and medium scale deserves more priorities before urban planning and construction. In addition, the traditional urban space design method tends to focus too much on the space form while ignore the ecological flow. The urban planners determine the ecological space layout based on the status quo of ecological land distribution, the service radius of the urban green space in addition to the urban space configuration and so on. Especially they attach insufficient consideration to the horizontal and vertical flow of the ecological elements and always block the natural process with the geometrical composition. The ecological functions of the ecological land in isolated planning layout and the ecological corridors fragmented by construction land including the urban road are largely weakened, which result in a series of urban ecological security problems of the city. The cross-scale ecological security pattern of the landscape between the built up area to the city center and its relationship with the ecological flow boast great significance. The ecological security pattern of the construction land should be studied in the perspective of city center scale (Fig. 1). The construction of the ecological security pattern of the landscape is a scientific method which adopts the landscape ecological approach to maintain regional ecological security and to ensure the completion and health of the regional ecological system (Li et al. 2004; Yang 2014; Yang et al. 2011; Yu et al. 2009; Hu et al. 2011). Therefore, the paper breaks through the previous studies of only establishing the ecological security pattern of large scale landscape, selects the Harbin city center, the capital of Heilongjiang Province of rapid social and economic development and increasingly acute ecological environment problems as the research target, applies the ecological methods to build the ecological security pattern of the landscape in the downtown area of Harbin and implements the concept of ecological civilization throughout the course of urban planning in order to provide scientific basis for the general planning and accomplish the ultimate goal of ensuring sustainable urban development (Noor et al. 2014).

\section{Material and methods}

\subsection{Study area}

Harbin is located in the north of northeast China, central and southern in Heilongjiang and along the Songhua river, with a regional geography of east longitude between $125^{\circ}$ $42^{\prime}$ and $130^{\circ} 10^{\prime}$ and north latitude between $44^{\circ} 04^{\prime}$ and $46^{\circ}$ $40^{\prime}$. The city has altogether 8 districts namely Daoli, Daowai, Nangang, Xiangfang, Pingfang, Songbei, Hulan, Acheng, and 10 countries called Shuangcheng, Shangzhi, Wuchang, Binxian, Bayan, Yilan, Fangzheng, Mulan, Tonghe, Yanshou under its jurisdiction. In 2011, its area totaled 5.31 square kilometers and its population numbered 9,899 million, including the urban area of 7,086 square kilometers and the urban population of 4,751 million. According to the "Urban Master Plan of Harbin (2011-2020)", the Harbin city center totaled an area of 4,187 square kilometers. In view of data acquisition, this article concentrates on the research on $\mathrm{Da}$ oli District, Nangang District, Xiangfang District, Pingfang District, Songbei District, the west of the Ashi River in Daowai District, and the south of the Hulan River in the Hulan District that gross an area of 1,694 square kilometers (Table 1 and Fig. 2).

In this paper, the data of landscape concerning land use source from the "Urban Master Plan of Harbin (20112020)". Based on the ArcGIS Platform and by means of data format conversion, the paper also establishes the database of the landscape for land use in the Harbin city center as the basic data for research.

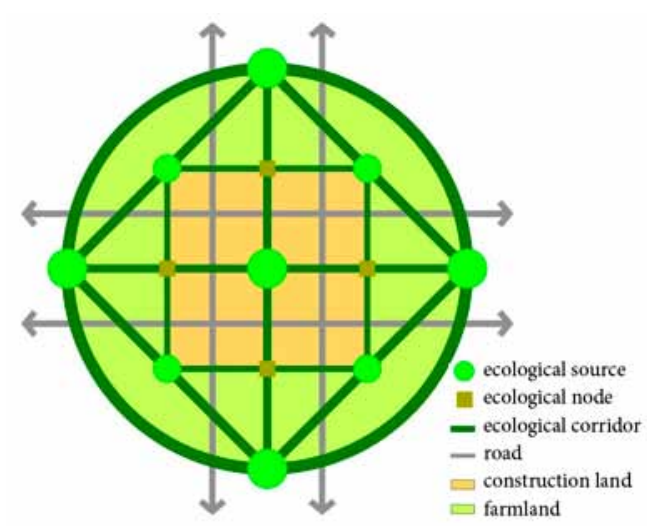

Fig. 1. The ecological security pattern of urban landscape

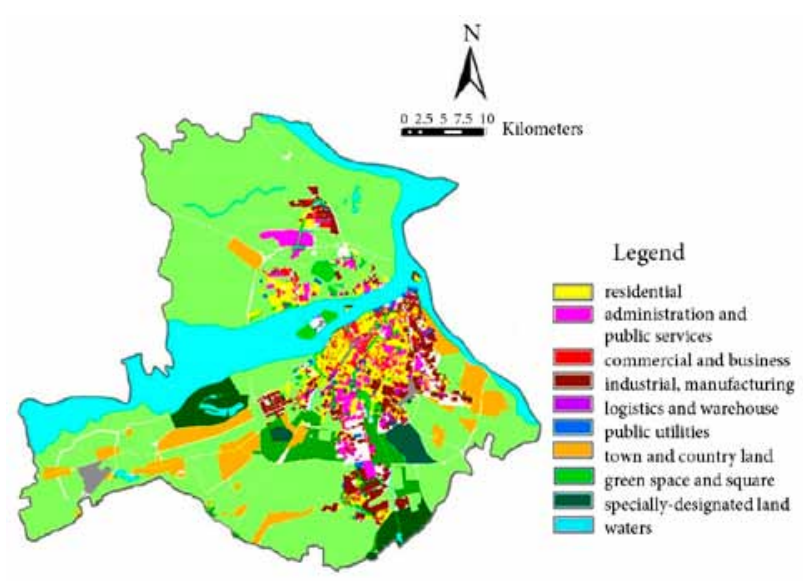

Fig. 2. The status quo map of the research area 


\subsection{Field survey}

In this paper the cumulative cost distance model is used to build the ecological security pattern of the Harbin city center, determining the function value of the ecosystem of various types of land in the city center to build the resistance surface, look for the minimum resistance between two source channels namely the ecological corridors, define the intersection of the corridors as the ecological nodes and establish the ecological security pattern of the landscape in the research area on the basis of the ecological source, ecological corridor and ecological nodes.

\subsection{Selection of the ecological source}

In landscape ecology, the landscape type that is able to promote landscape process development is known as the "source". It gives full scope to the natural ecological functions and has the land featuring important ecosystem service functions, fragile ecological environment and high ecological sensitivity, such as a large area of forest land, grassland, water area, etc. "Source" landscape can promote and maintain the role of the landscape function and has a certain continuity and space expansion (Yue et al. 2007). In this paper the protected "source" refers to the green land, the scenic spots, the waters and the forest land in the city center that protect the urban landscape ecology from the perspective of city center planning included in the urban master planning.

\subsection{Building of the resistance surface}

The ecological flow is the carrier of the ecological process and the decisive factor of the stability of the ecological function. The smoothness degree of the ecological flow directly reflects whether the landscape pattern is reasonable and the structure is stable. The operation of this kind of ecological flow needs to overcome resistance from different landscape elements and the resistance surface reflects the trend of the operation of the ecological flow. The minimum cost distance refers to the cost or the power to overcome the resistance from the "source" through different landscape groups (Yang et al. 2011; Yu et al. 2009). The cumulative cost distance model can be applied to analyze and simulate the operation of the ecological flow. It is the effective form to reflect the influence of different types of land use on the ecological flow. The spatial analysis of the cost distance module based on the ArcGIS platform calculates the lowest cumulative cost distance of each landscape unit to the nearest source through the cost surface, builds the cumulative cost distance model, and reflects the space running of the source landscape and displays the spatial spanning characteristics of all landscape types. The accumulative cost distance model is used to indicate the cumulative cost distance, primarily considering such factors as the ecological source, the distance and the surface resistance, as shown in the Equation (1):

$$
C_{i}=\Sigma\left(D_{i} \times F_{i}\right), i=1,2, \ldots, n ; j=1,2, \ldots, m,
$$

where: $C_{i}$ is the cumulative cost from the $i^{\text {th }}$ landscape unit to the source unit; $D_{i}$ is the true distance from the

Table 1. The land area and the value of the ecological function

\begin{tabular}{|c|c|c|c|c|c|}
\hline \multicolumn{4}{|c|}{ Type of land use } & \multirow{2}{*}{$\begin{array}{c}\begin{array}{c}\text { Floor space } \\
\left(\mathrm{hm}^{2}\right)\end{array} \\
7485\end{array}$} & \multirow{2}{*}{$\begin{array}{c}\begin{array}{c}\text { Value of the } \\
\text { ecosystem } \\
\text { function }\end{array} \\
2.56\end{array}$} \\
\hline \multirow{12}{*}{$\begin{array}{l}\text { Construction } \\
\text { land }\end{array}$} & \multirow{9}{*}{$\begin{array}{l}\text { Land for } \\
\text { construction } \\
\text { for urban } \\
\text { and rural } \\
\text { residence }\end{array}$} & \multirow{8}{*}{$\begin{array}{l}\text { Urban } \\
\text { construction } \\
\text { land }\end{array}$} & Residential land & & \\
\hline & & & $\begin{array}{l}\text { Land for public management and public } \\
\text { service }\end{array}$ & 3282 & 2.80 \\
\hline & & & Land for facilities for commercial services & 1090 & 2.00 \\
\hline & & & Industrial land & 5527 & 1.20 \\
\hline & & & Land for logistics warehousing & 576 & 1.20 \\
\hline & & & Land for roads and traffic facilities & 2338 & 3.00 \\
\hline & & & Land for public facilities & 362 & 1.60 \\
\hline & & & Green space and land for square & 2282 & 7.00 \\
\hline & & \multicolumn{2}{|c|}{ Land for construction of towns and villages } & 8622 & 1.20 \\
\hline & \multicolumn{3}{|c|}{ Land for regional transportation facilities } & 1157 & 3.00 \\
\hline & \multicolumn{3}{|c|}{ Special use of land } & 1783 & 1.20 \\
\hline & \multicolumn{3}{|c|}{ Land for other construction purposes (scenic area) } & 4410 & 8.00 \\
\hline \multirow{3}{*}{$\begin{array}{l}\text { Land unfit for } \\
\text { construction }\end{array}$} & \multicolumn{3}{|l|}{ Waters } & 26398 & 10.00 \\
\hline & \multicolumn{3}{|c|}{ Land for agriculture and forestry (forest land) } & 4534 & 10.00 \\
\hline & \multicolumn{3}{|c|}{ Land for agriculture and forestry (cultivated land) } & 9953 & 5.00 \\
\hline
\end{tabular}


$i^{\text {th }}$ landscape unit to the source unit; $F_{\mathrm{j}}$ is resistance value of the $j^{\text {th }}$ landscape unit; $n$ is the total amount of the basic landscape unit.

\subsection{Generation of the ecological corridors}

Ecological corridor is the linear or strip ecological landscape element different from the surrounding landscape matrix. It is the main channel for the diffusion of the ecological flow of the landscape. Shown in the chart of the resistance surface, the corridor is the channel of the least resistance between the two adjacent "sources" and the easiest way to contact between two "sources" of low resistance. According to the different security levels, there may be one or more corridors between the sources which function as the efficient channels and the contact methods between the ecological flows. There should be at least one corridor between the two "sources". The corridor is conducive to the flow of landscape ecological flow between the "sources" and between the "source" and the matrix. The corridor linking the native vegetation is beneficial for the diffusion of the species beyond the landscape scope and the running of the ecological flow (Adriaensen, Chardon 2003; Li et al. 2011).

\subsection{Creation of the ecological nodes}

The ecological node refers to the space connecting the two adjacent ecological sources, and the location where landscape ecological process plays a key role. The ecological node reflected from the chart of the resistance surface is the tangent point of the equal resistance lines with the adjacent "source" as the center. Generally it is of the weakest ecological function and boasts a vital significance to control the landscape ecological flow (Adriaensen, Chardon 2003; Li et al. 2011). In the overall urban planning, the ecological nodes in the built up area can usually represent the city parks.

\section{Results and discussion}

\subsection{The construction of the ecological security pattern of the landscape of the city center}

\subsubsection{The extraction of the ecological source}

According to the above methods to determine the ecological source, the present large natural ecological corridor is taken as the ecological source. At the same time, in view of the research area in the article, the water area, the scenic spots, the forest land and the urban green space of more than 10 hectares also has a certain ecological function in the scale So they can be regarded as the ecological source of the research area, mainly including the Songhua River, Hulan River, Ashi River, the Sun Island Scenic Spot, and the Botanical Garden, etc.

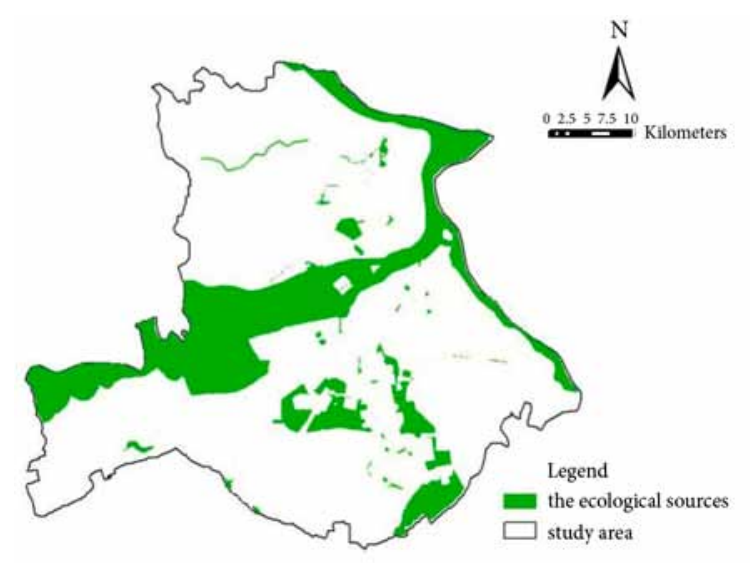

Fig. 3. The chart of the ecological source in the research area

The ecological source boasts a high value to protect the urban ecological environment.

Depending on the type of the ecological source selected, the ArcGIS software is adopted in the research area to extract the corresponding layer of landscape type in the landscape database and generate the layer of the ecological source in the research area. The extraction result of the ecological source is $37,624 \mathrm{~km}^{2}, 22.21 \%$ of the total research area (Fig. 3).

\subsubsection{The resistance surface}

After determining the ecological source, the cumulative cost distance model was used to build the resistance surface. The key of the model is to evaluate all kinds of land in the research area landscape and their resistance and determine the ecological function of the landscape for different use. Some existing literature interprets the service value of the ecosystem of the "urban construction land" as negative. Such judgment will exert significant impact on the investment and model of urban ecological construction, and so on (Swartjes et al. 2008). In fact all kinds of land within the urban construction land also have a certain degree of the ecological service value. The paper considers the influence of the type, quantity and space distribution of landscape, as well as the landscape pattern on the change of the ecological environment of land use. Based on the theory of "source - convergence" and referring to the research data of relevant research literature on the specific indicators of the service function of the landscape ecosystem of different types at the same time, the paper assigns the value of the service functions of the landscape ecosystems of different land. Assign 10 to the water and forestland which generate the biggest effects upon the ecological environment; the rate of the residential land in accordance with the "Formulation Standards of the Regulatory Detailed Planning of Heilongjiang Province" should account for more than $32 \%$, and the residential land greening gives priority to grass and shrubs whose ecological function 


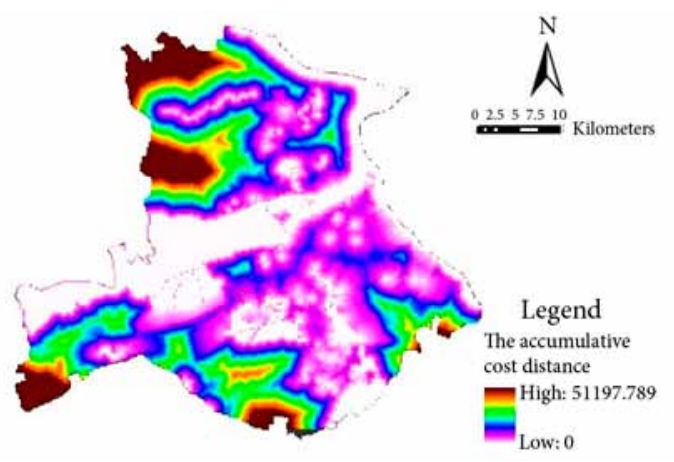

Fig. 4. The surface map of the cumulative cost distance

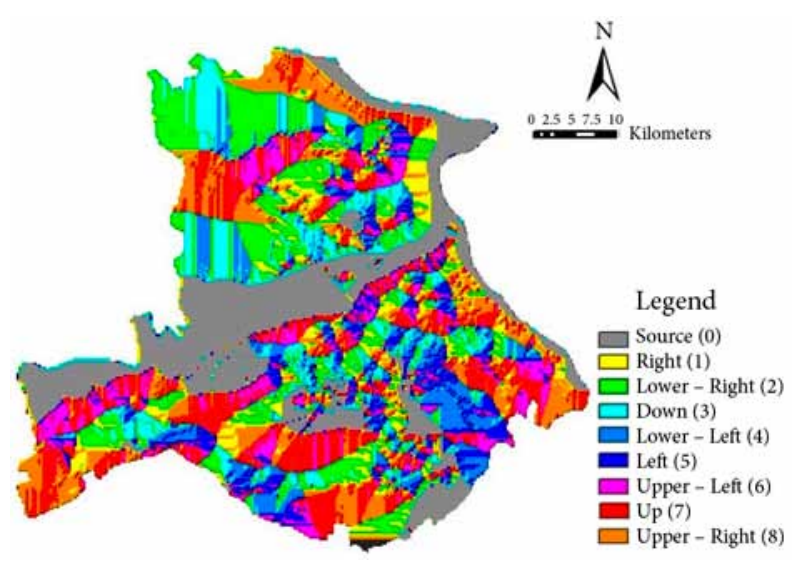

Fig. 5. The directional diagram of the cumulative resistance

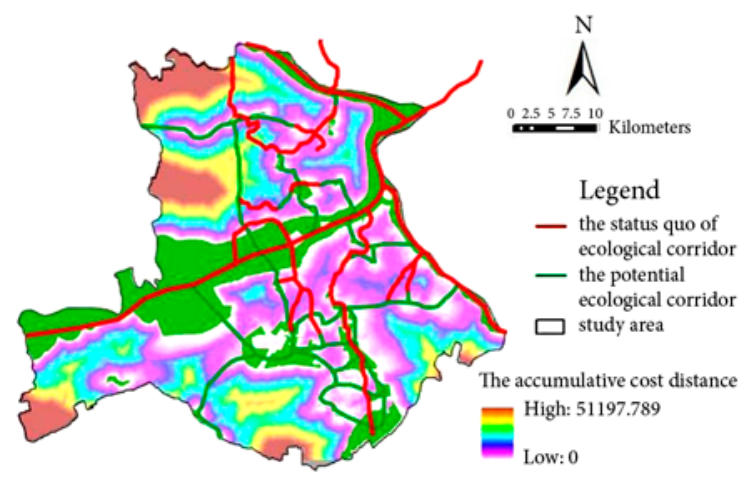

Fig. 6. The map of potential ecological corridor

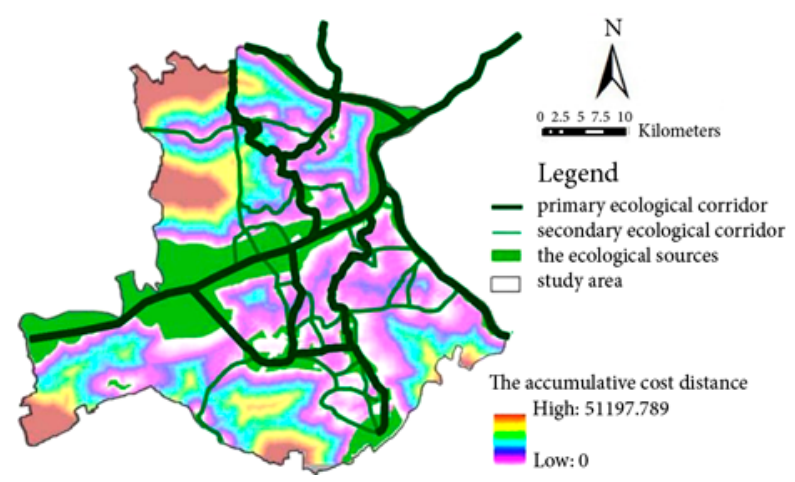

Fig. 7. The map of the grade of the ecological corridor can take up $80 \%$ of that of the forest ecosystem, so as to determine the residential land ecosystem function value to be 2.56 (Zhou 2001); Similarly, other land referring to the "Formulation Standards of the Regulatory Detailed Planning of Heilongjiang Province", the "Urban Road Landscape Planning and Design Code" and the "Industrial Project Construction Land Control Indicators" (Zhou 2001) and other related normative documents for the ratio of green land of all kinds, the value of ecosystem service function is 2.8 for the land for public administration and public service, 2 for commercial and service facility, 1.2 for industry, 1.2 for warehousing, 3 for traffic facilities and road, 1.6 for public facilities, 7 for green space and square, 1.2 for rural construction, 3 for regional transportation facilities, 1.2 for special use, 8 for scenic spots and 5 for arable land (Table 1). The directions of the cumulative cost distance surface and the cost resistance are shown in Figure 4 and Figure 5.

\subsubsection{The ecological corridor}

There are chiefly two types of ecological corridors in urban planning: One kind is the status quo ecological corridor in the city center planning stage, which is relatively easy to identify, generally including the river system and its beaches, natural or artificial zonal forest land etc. Such a kind of ecological corridor needs to be strengthened and improved in the land layout; the other is the potential ecological corridor, which is often easy to ignore in the urban planning. The ecological corridors play a crucial role in the operation of the ecological flow and the maintenance of the urban ecological environment. This article mainly aims to differentiate the potential ecological corridors to build an ecological security pattern for the urban landscape, and give a further guidance to the city center land layout planning. There are one or more valley lines of lower cumulative resistance between the protecting "source" and any other "source". It is commonly believed in the possible range of corridor, the more the better, and one more corridor is equivalent to an increase of one more alternative approach to the spatial motion of the species, and to the reduced risk of a closure and segmentation that generates more stability of the ecosystem safety.

Based on determining the direction of the cumulative cost distance surface and the cumulative resistance direction and on the use of the ArcGIS software, the path of the minimum relative weighting costs of the space distance and the resistance value is generated, namely, the potential ecological corridor (Fig. 6). At the same time, the ecological corridors between the ecological sources of more than 50 hectares are identified as the primary ecological corridor with other corridors defined as the secondary ecological corridors (Fig. 7). 


\subsubsection{The ecological nodes}

The ecological node is positioned in the ecological distribution of landscape space for land use and plays a vital role in the connection of the adjacent landscape of ecological source. In terms of space distribution, the ecological node is relatively fragmented, which would lead to a difficult area of material and energy circulation. So, in establishing the regional ecological node, we should improve the land use from the perspective of the ecological connectivity of the landscape to achieve the purpose of ecological circulation by promoting the spread of the material and energy.

By using domain analysis and classification, and other functions of the ArcGIS spatial analysis and setting reasonable domain values, respectively from the minimum cumulative cost distance between the source and the maximum cumulative cost from the path of the surface of the grid, the grid surface was extracted; through grid computing the intersection of the above two was extracted; finally by combining the need of urban planning, the spatial distribution of the ecological node is determined. The ecological node is the intersection point of the ecological corridors, and therefore, the level of ecological node is closely related to the level of ecological corridors. At the same time, according to the actual situation in the research area, the ecological node is divided into three parts (Fig. 8). The primary ecological node is the intersection between primary ecological corridors, located in the key position exerting the most effects on the ecological connectivity of the landscape. The secondary ecological node is the intersection between the primary and secondary ecological corridors, whose ecological function is weaker than that of the primary node. The tertiary is the intersection between the secondary ecological corridors, where the function of the ecological connectivity of the landscape is the weakest. The construction of the ecological node boasts important referential value for the general ecological planning of the city and plays an influential role in protecting the regional ecological environment.

\subsection{The spatial structure of the city center based on the security pattern and the protection strategies of the landscape}

\subsubsection{The ecological security problems of the landscape in the current urban planning}

Superpose the chart of the ecological corridor in the research area and the ecological node with the city planning diagram (Figs 9, 10). According to the results, the conventional urban ecological land planning lacks in-depth study of the land layout of the ecological security pattern of the landscape of the city center. Within the scope of the city center, the ecological corridor planning judges the current situation of the ecological corridor mainly through the status quo of the ecological basement. Urban planning does not take potential ecological corridors in the area and the spatial distribution of ecological node into account. This leads to the ignorance of urban construction for the protection of the potential ecological corridor and the ecological node, which partly damages regional ecological environment security. Therefore, the determination of reasonable overall urban planning should consider the

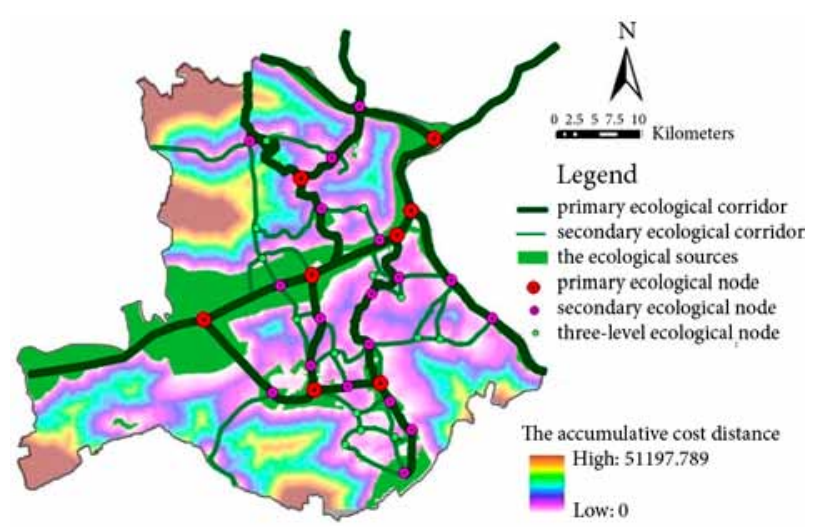

Fig. 8. The graph of the ecological nodes

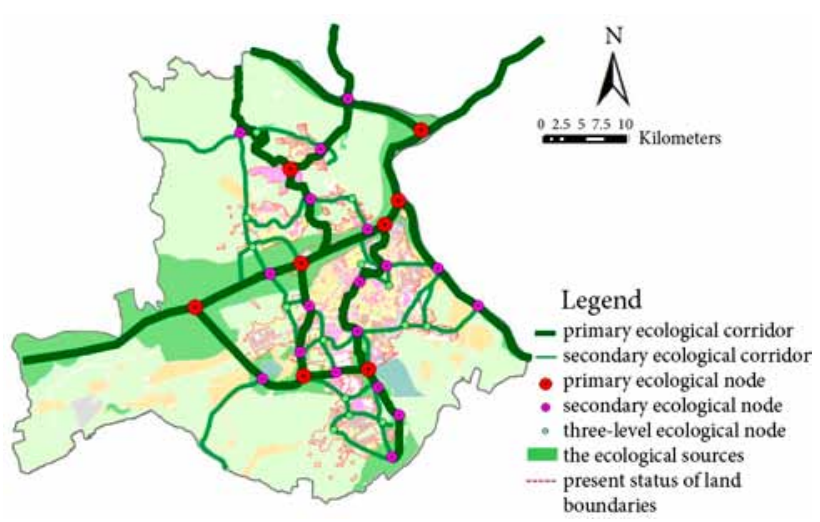

Fig. 9. The overlay chart of the diagram of the ecological security pattern of the landscape in the research area and that of the current status of the city

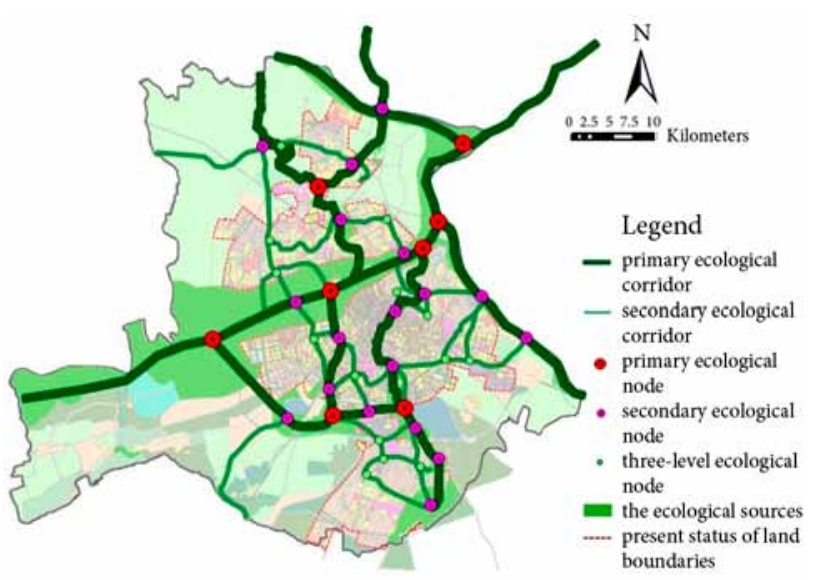

Fig. 10. The overlay chart of the diagram of the ecological security pattern of the landscape and that of the urban planning 
ecological security pattern of the regional landscape. It is necessary to firstly determine the ecological corridor and the ecological nodes in line with their spatial distribution and make reasonable plans for land use on this basis.

\subsubsection{The space structure of the city center based on the ecological security pattern of the landscape}

The spatial pattern of the city center based on the ecological security pattern of the landscape was built as in Figure 11 was on the basis of the result of the grade diagram of the ecological corridor of Harbin city center and that of the level of the ecological node and in combination with the practical situation of the research area. The Harbin city center, with Songhua River, Hulan River, Ashi River running through, stands as the ecological source area and ecological corridor of the strongest technological function. In addition, there are many primary ecological corridors on the southern and northern sides of the Songhua $\mathrm{Ri}$ ver. The ecological land use planning should offer adequate protection to these primary ecological corridors and strictly prohibit urban development and construction. So it should be planned as the ecological source, including water, green land and forest land, etc. As to the areas of primary ecological node, if the large ecological source is located there, the plan should just retain its current attribute. As to the primary ecological node beyond the location of the large ecological source, in combination with the practical situation of land use, it should be planned to be large city park green land. What's more, there are several secondary corridors, tertiary and secondary nodes in the city center. The ecological construction should place priority to the secondary ecological corridors and the land whose current status cannot be changed in a short time can be temporarily retained. There are a large number of such areas whose purpose for construction cannot be changed in the present situation in Harbin city center. We should, therefore, during the planning, determine the width of the ecological corridor, delimit the ecological corridor to protect the red line, and then realize the

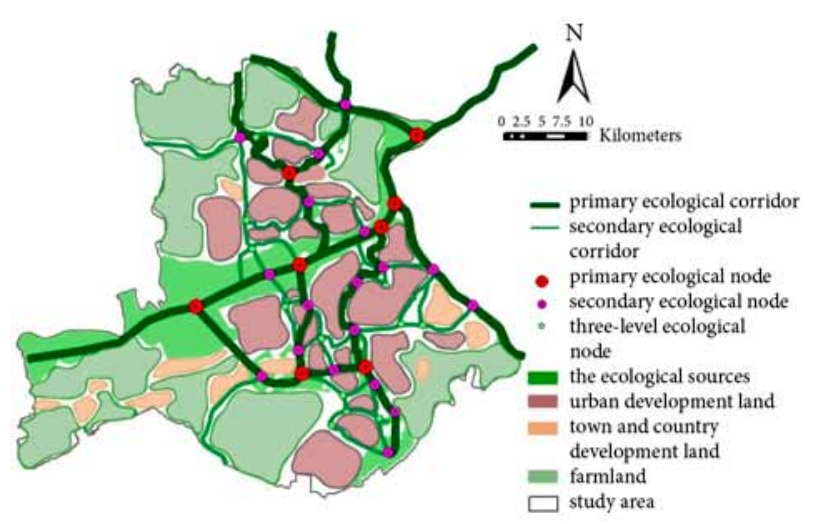

Fig. 11. The graph of the spatial pattern of the research area protection of the existing secondary ecological corridors. Also, the secondary and tertiary ecological nodes should be planned as the land of ecological function whose scale can be appropriately smaller than the level of land for the primary ecological nodes. It is strictly prohibited from being applied in land for urban construction unless in special circumstances. In conclusion, in order to protect and maintain the regional ecological environment, the current status of land use and the spatial distribution of ecological source, ecological corridor and ecological nodes in the research area should be taken into overall consideration to build the spatial pattern of Harbin city center based on the ecological security pattern of the landscape and divide the city center into four parts: the ecological source, the land for urban construction, the land for village and town construction and the farmland. The ecological source and farmland need to be protected rather than occupied in the construction and development.

\subsection{The strategy to protect the ecological security pattern of the landscape in the city center}

\subsubsection{The strategy to ecological source protection}

The development and construction of the ecological source in any form should be forbidden and the ecological source area should deserve ecological restoration and ecological protection. The ecological source within the construction land should pin priority to ecological restoration. As the urban ecological infrastructure, the ecological source should improve the rate of green space, reduce the rigid pavement and the recreation facilities and appropriately increase the landscape diversity. The ecological line should be designated to avoid significant impact of human activities on the ecological source within the red line. In the process of urban planning and construction, attention should be pinned to the "point" and "line" to form the ecological flow and protect the healthy ecological flow. For the ecological source outside the construction land, ecological protection should deserve priorities. The scenic areas mostly distribute outside the construction land, and we should pay attention to protecting the ecological vegetation and water source, such as the scenic spots and the botanical gardens, strictly control the number of visitors and attach attention to the sewage and garbage treatment during tourism to avoid pollution. The forest is an important ecological source and we should give full play to the ecological, economic and social benefits of the forest, strictly control its purposes, actively replenish forest land and protect the ecological diversity. Waters can provide support and guarantee flood and draining water logging, water supply, ecological water environment security and so on. To protect the waters, we shall establish a wetland reserve, protect the existing wetland, gradually restore the degraded wetland, keep biodiversity, reasonably cultivate 
water holding plant, avoid water pollution and intensify urban sewage treatment.

\subsubsection{The strategy to ecological corridor protection}

The construction of the ecological corridors can strengthen the connectivity and protection of various landscape in the area and solve the problems of landscape fragmentation to a larger extent. For primary ecological corridors, the urban green land or waters should be planned and all sorts of urban construction activities should be strictly prohibited. At present, the "Standardization Administration of The People 's Republic of China (2007)" defines rivers beyond the category of construction land and the green space on both sides as the land for urban construction to build quantities of non-ecological facilities. This will lead to the decrease of the river system corridor's ecological function. We should consider the green land on both sides of the ecological corridor of the river system uniformly as the ecological land, rather than as the urban construction land. The secondary ecological corridors should be planned to be the land of green ecological functions and a few urban recreation facilities can be appropriately built.

As for the ecological corridor in the present situation within the scope of the built up area, the status quo of ecological corridors of excessive urbanization should gradually go through rebuilding to restore the ecological functions. As for the ecological corridor outside the scope of the built up area, ecological corridor buffer shall be established and the ecological protective red line shall be delimited. The urban roads and the advanced ecological corridors should adopt the form of interchanges to protect healthy ecological flow. The potential ecological corridor in the scope of the built up areas should be regarded as ecological infrastructure to delimit the red line of the potential ecological corridor during urban planning, and gradually build the ecological corridors during urban construction and renovation. For the potential biological corridors outside the built up areas, the red line of the ecological corridor should be delimited in a bid to prohibit the construction of agricultural production facilities from destroying the ecological corridor, improve the landscape connectivity, and ensure the function of sound ecological flow of the ecological corridors (Noor et al. 2014).

\subsubsection{The strategy to ecological node protection}

As the intersection of the ecological corridors, the ecological node should be constructed and repaired with land of high ecological value. Outside the built up area, the ecological nodes should be forbidden from urban construction to gradually improve their ecological function; the ecological nodes in the built up areas whose use cannot be changed can be temporarily retained. During urban construction, the ratio of green land should be enhanced and the function of city of low impact should be established. As for the status quo of the ecological nodes in the built up areas the functions of leisure in the city should be gradually reduced to give full scope to their dominant ecological function.

\section{Conclusions}

The paper adopts the method of landscape ecology to select the ecological source, construct the ecological corridor and generate the ecological node, build the ecological security pattern of the landscape of the research area, and direct the ecological land planning in the center of the research area. The research gets to the following conclusions:

Determine the ecological source. This paper takes the large status quo of the natural ecological corridor and the water area, the scenic spots, the forest land and the urban green space of more than 10 hectares as the ecological source totaling an area of $37,624 \mathrm{hm}^{2}$.

Create the resistance surface. Assign the value of the ecosystem functions of land of all kinds and use the cumulative cost distance model to create the resistance surface.

Generate the ecological corridors. Adopt the cumulative cost distance surface and cumulative resistance direction to create the ecological corridor in the research area. The ecological corridor is divided into primary ecological corridor and secondary ecological corridor.

Create the ecological nodes. Determine the spatial distribution of the ecological nodes and classify the ecological nodes into the primary, secondary and tertiary levels through calculating the grid based on the grid surface of the minimum cumulative cost distance and the maximum cumulative cost distance path between the sources.

Build the spatial pattern of the city center. Build the spatial pattern of the city center on the basis of the ecological security pattern of the landscape which is also the fundamental condition to restrain urban planning and construction so as to direct the planning of the city center.

Make the strategy of the protection of the ecological security pattern of the landscape. Put forth the specific strategies to the protection of the ecological land of the city center respectively from the aspects of the ecological origin, the ecological corridor and the ecological node as a reference for the preparation of city planning.

\section{Recommendations}

The safety of the urban ecological land is the fundamental guarantee for the healthy development of the city. The existing research mostly focuses on the large scale regional ecological security problems while rarely on ecological security of small and medium scale urban land from the perspective of landscape ecology. The research idea of this 
article is to develop the planning to use the urban ecological land before the preparation of the overall urban planning in order to restrain the destruction of the ecological environment in the development of urban construction and construct the ecological security pattern of the landscape based on the theory of landscape ecology and the research method in order to guide ecological land use planning of the city center in the research area, break through the situation lacking landscape ecology to guide urban planning and fully tap the potential ecological functions of land use. The results have important guiding significance for the protection of small and medium scale regional ecological environment. In this paper, the study of the ecological corridor and the ecological node is limited to the level of tiering, rather than the radiation size of the ecological corridor and the ecological nodes at all levels. As a result, it will be the main content of future study to build the ecological corridor and the ecological node buffer in combination with the practical situation of the research area and direct the preparation of the overall urban planning more specifically.

\section{Disclosure statement}

The authors certify that there is no conflict of interest with any financial organization regarding the material discussed in the paper.

\section{Acknowledgments}

This research is supported by UMRG (RG257-13AFR) IPPP (PG038-2013B) and FRGS (FP038-2013B).

\section{References}

Adriaensen, F.; Chardon, J. P. 2003. The application of the "leastcost" modeling as a model of functional landscape, Landscape and Urban Planning 64: 233-247.

http://dx.doi.org/10.1016/S0169-2046(02)00242-6

Hu, D.; Zong, Y.; Xu, W. 2011. Research on the construction of the ecological security pattern of the landscape in the new urban region development based on ecology network analysis, Proceedia Environmental Science 18: 10-20.

Li, H.; Yi, Na.; Yao, W. 2011. Shangri-La county ecological land use planning based on landscape security pattern, Acta Ecologica Sinica 31(6): 5928-5936.

Li, X.; Ma, K.; Fu, B. 2004. The regional pattern for ecological security (RPES): designing principles and method, Acta Ecologica Sinica 24(5): 1055-1062.

Ma, K.; Fu, B.; Li, X.; Guan, W. 2004. The regional pattern for ecological security (RPES): the concept and theoretical basis, Acta Ecologica Sinica 24(4): 761-768.
Noor, M. J.; Ahmad, M.; Zafar, M.; Sarfraz, M.; Yusoff, I.; Alias, Y.; Ashraf, M. A. 2014. Floristic and ethnoecological diversity in various habitats of a semi-arid area in the Chakwal district (Pakistan), with special emphasis on medicinal plants, Plant Ecology. http://dx.doi.org/10.1007/s11258-014-0384-1

Qin, X.; Duan, X.; Yang, J. 2010. Scenario simulation of urban land use allocation and scheme evaluation based on GIS: A case study of Taicang City, ACTA Geographica Sinica 6(9): 1211-1219.

Ren, X.; Ren, S. 2009. Study on planning principle and method of urban pattern for ecological security, Chinese Landscape Architecture 7: 73-77.

Rong, B.; Li, D.; Xie Y. 2011. On mesoscale and microscale land planning methods, Acta Ecologica Sinica 31(18): 5351-5357.

Standardization Administration of The People's Republic of China. 2007. Current land use classification GB/T 21010-2007. Beijing: China Zhijian Publishing House.

Swartjes, F. A.; Carlon, C.; de Wit, N. H. S. M. 2008. The possibilities for the EU-wide use of similar ecological risk-based soil contamination assessment tools, Science of the Total Environment 406(3): 523-529.

http://dx.doi.org/10.1016/j.scitotenv.2008.07.034

Urban Master Plan of Harbin (2011-2020). Harbin Urban and Rural Planning Bureau, Harbin, China [online], [cited 8 December 2014]. Available from Internet: http://www.upp. cn:8084/english/view/Planning1/article/303957.html

Yang, B. 2014. Review and prospect on urban spatial pattern research in the view of ecological security, Ecological Economy 30(3): 67-71.

Yang, J.; Zhou, S.; Wang, X. 2011. An overview of the study on ecological land, Journal of EMCC 21(2): 33-35.

Yang, P. 2010. Ecological urbanism: scale, flow and design. Beijing: China Architecture \& Building Press. 67 p.

Yu, K.; Qiao, Q.; Li D.; Yuan, H.; Wang, S. 2009. Ecological land use in three towns of eastern Beijing: A case study based on landscape security pattern analysis, Chinese Journal of Applied Ecology 20(8): 1932-1939.

Yue, D.; Wang, J.; Liu, Y. 2007. Landscape pattern optimization based on RS and GIS in northwest of Beijing, ACTA Geographica Sinica 62(11): 1223-1231.

Zhou, L. 2001. The enlightenment of western urban planning theory development for China, Foreign Urban Planning 1: 34-37.

Zulkifley, M. T. M.; Ng, N. T.; Abdullah, W. H.; Raj, J. K.; Ghani, A. A.; Shuib, M. K.; Ashraf, M. A. 2014a. Geochemical characteristics of a tropical lowland peat dome in the Kota Samarahan-Asajaya area, West Sarawak, Malaysia, Environmental Earth Sciences 73 (4): 1443-1458. http://dx.doi.org/10.1007/s12665-014-3504-2

Zulkifley, M. T. M.; Fatt, N. T.; Raj, J. K.; Hashim, R.; Ashraf, M. A. 2014b. The effects of lateral variation in vegetation and basin dome shape on a tropical lowland peat stabilization in the Kota Samarahan-Asajaya area, West Sarawak, Malaysia, Acta Geologica Sinica, 88 (3): 894-914. http://dx.doi.org/10.1111/1755-6724.12245 
Zhang YUANJING is a Ph. D. student of the School of Resources and Environment of Northeast Agricultural University, director of Heilongjiang Urban Planning Surveying Design and Research Institute and researcher in ecological and sustainable urban planning. His current research interest is urban and regional planning.

Yu BINYANG, Deputy Director of the Audit Office of the Ministry of Housing and Urban-Rural Development of the People's Republic of China

Muhammad Aqeel ASHRAF is Senior Lecturer of Environmental Geochemistry at Department of Geology, Faculty of Science, University of Malaya, 50603 Kuala Lumpur, Malaysia. His current research interests include environmental geochemistry, soil science, soil contamination, soil quality standards, air borne contamination, methods of geochemical mapping at different scales, and medical geology. 